\title{
DETECTION OF CHROMOSOMAL BREAKS INDUCED BY THIACLOPRID IN HUMAN LYPMHOCYTES AND DETECTION OF DOUBLE-STRAND BREAKS BASED ON $\gamma \mathrm{H} 2 \mathrm{AX}$ HISTONE PHOSPHORYLATION
}

\author{
Samková, G., Galdíková, M., Schwarzbacherová, V., Koleničová, S. \\ Department of Biology and Genetics \\ University of Veterinary Medicine and Pharmacy in Košice, Komenského 73, 04181 Košice \\ Slovakia \\ martina.galdikova@uvlf.sk
}

\section{ABSTRACT}

Thiacloprid, a neonicotinoid insecticide, is widely used to control various species of pests in the current agriculture of today. The potential genotoxic effects of thiacloprid on human peripheral blood lymphocytes were investigated in vitro by chromosome aberrations (CA), and double-strand breaks (DSB), which were detected by the phosphorylation of $\gamma \mathrm{H} 2 \mathrm{AX}$ histone. Human peripheral blood lymphocytes were exposed to $30,60,120,240$, $480 \mu \mathrm{g} \cdot \mathrm{ml}^{-1}$ doses for the last 24 and 48 hours of culture. Thiacloprid increased CA at the concentrations of 240, $480 \mu \mathrm{g} \cdot \mathrm{ml}^{-1}(\mathrm{P}<0.05)$, but these results did not confirm genotoxicity. The mitotic index (MI) was important to us; it served as a basis for the confirmation of the cytotoxicity of this insecticide. During $\mathbf{4 8}$ hours of culture, at the concentration of $480 \mu \mathrm{g} \cdot \mathrm{ml}^{-1}$, its value rapidly decreased (0.42) $(\mathrm{P}<0.001)$, which did not allow us to analyse the results because of the high cytotoxic response.
Key words: acetylcholinesterase; $\gamma \mathrm{H} 2 \mathrm{AX}$ histone; chromosomal aberrations; neonicotinoids; phosphorylation; thiacloprid

\section{INTRODUCTION}

Humans have inhabited the Earth for more than 3 million years, while the insects have existed for at least 250 million years. Nowadays we can only guess that our ancestors used various methods against invasive insects, such as setting up smoke fires, rubbing the skin with mud or dust, using bile of a green lizard to protect apples against worms and decay, extracts from spice and tobacco, soapy water, white powder, vinegar, turpentine, fish oil, salt brine, lye and many others [10]. However, now we have more effective methods to control the insects. These methods are chemical compounds-insecticides. Neonicotinoids are the most successful new class of insecticides which are referred to as orthosteric modulators nAChR [3]. These chemical com- 
pounds are derived from nithiazine containing a nithromethylene functional group. As it was discovered in 1984, the effect of nithiazine lies in postsynaptic agonic action on acetylcholine receptor, the same case as nicotin. Nithiazine had the required specificity (i. e. low toxicity for mammals), but was not photostable, so it was not commercially successful $[8,9]$. The invention of imidacloprid, the most important neonicotinoid insecticide, was launched by the discovery of 1-(6-chloro-3-pyridylmethyl)-2-nitromethylenimidazolidine [5]. Its favourable characteristics made it a commercial blockbuster, followed by clothianidin, dinotefuran, acetamiprid, thiamethoxam and thiacloprid.

The reason for the development of this new insecticide class was that they would be more effective and less harmful for non-target organisms than their predecessors - nicotinoids. Thus, the mechanism of their action is blocking the insect post-synaptic nicotinic acetylcholine receptors, which should make them non-toxic compounds for vertebrates. After blocking the receptors, the transfer of impulses is impossible and so the organism is subjected to paralysis, even death. Later the neonicotinoids got under criticism for their possible adverse or toxic effects.

The aim of our study was to evaluate chromosome aberrations induced by thiacloprid and detect double-strand breaks on the basis of $\gamma \mathrm{H} 2 \mathrm{AX}$ phosphorylation in human peripheral blood lymphocytes in vitro.

\section{MATERIALS AND METHODS}

\section{Detection of chromosomal breaks induced by thiacloprid in human lymphocytes}

The whole blood culture of a 21-year-old woman was performed in $5 \mathrm{ml}$ of a culture medium during 72 hours in a thermostat with a temperature set on $38^{\circ} \mathrm{C}$. The components of the culture medium were RPMI 1640 containing Lglutamine and HEPES $15 \mu \mathrm{mol}$ (GE Healthcare Hyclone Lab, Utah, USA); $15 \%$ foetal calf serum (BoFeS, Sigma, Chemical Co. St. Louis, MO, USA), antibiotics (100 U.ml-1 penicillin, $0.1 \mathrm{mg} \cdot \mathrm{ml}^{-1}$ streptomycin and $0.25 \mu \mathrm{g} \cdot \mathrm{ml}^{-1}$ amphotericin) and the last component was mitogen phytohemagglutinin (PHA, $180 \mu \mathrm{g} \cdot \mathrm{ml}^{-1}$, Welcome, Dartfordt, England)-a Phaseolus vulgaris extract. The dedifferentiation (transformation to the immature cells-lymphoblasts, which divide and enter into mitosis) was carried out by PHA. Ethyl methanesulphonate (EMS, Sigma, St. Louis, MO, USA,
$250 \mu \mathrm{g} \cdot \mathrm{ml}^{-1}$ ), mitomycin C (MMC, Sigma, St. Louis, MO, USA, $0.4 \mu \mathrm{M}$ ) and thiacloprid at the concentrations of 30 , $60,120,240$ and $480 \mu \mathrm{g} \cdot \mathrm{ml}^{-1}$ were added for the last 24 and $48 \mathrm{~h}$ of the culture. Colchicine at the concentration of $5 \mu \mathrm{g} \cdot \mathrm{ml}^{-1}$ (Merck, Darmstadt, Germany)—a Colchicum autumnale alkaloid-was added for the last 90 minutes of the culture. Colchicine is a mitotic poison specifically inhibiting the formation of a mitotic spindle and thus stopping cell division in the metaphase of mitosis, during which the chromosomes are in the most condensed state and suitable for analysis. The activity of colchicine lasts until the addition of a fixation solution. After processing the cell cultures by fixation, we stained the slides according to Giemsa. Aberrations and MI were statistically evaluated by the $\chi$-square test.

\section{Detection of double-strand breaks on the basis of $\gamma \mathrm{H} 2 \mathrm{AX}$ histone phosphorylation}

Thiacloprid was added to the lymphocyte cultures at the concentration of $480 \mu \mathrm{g} \cdot \mathrm{ml}^{-1}$. To detect the $\gamma \mathrm{H} 2 \mathrm{AX}$ histone, we used the Anti-gamma H2A.X primary antibody (phosphor S139, ab26350) and the Goat Anti-Mouse IgG H\&L secondary antibody (Alexa Fluor ${ }^{\circledR} 488$, ab150113). Finally, the staining of the nuclei was carried out by DAPI + VECTASHIELD. The evaluation was performed manually by the fluorescence microscope NIKON Eclipse Ni-U with the Progres ${ }^{\circledR}$ camera and the METAFER automatic analysis module.

\section{RESULTS}

The results of the 24 and 48-hour cultures are summarized in Tables 1 and 2. During both 24 and 48-hour cultures we detected statistically insignificant results at the first 3 concentrations. At 240 and $480 \mu \mathrm{g} \cdot \mathrm{ml}^{-1}$ of thiacloprid, a slight DNA damage occurred $(\mathrm{P}<0.05)$, probably as a result of cytotoxic effects. Since we had not detected a statistically significant increase in chromosome aberrations depending on the lowest dose, the direct genotoxic effect of the given insecticide based on the conventional cytogenetic analysis had not been confirmed. Cytotoxicity was confirmed at the concentration of $480 \mu \mathrm{g} \cdot \mathrm{ml}^{-1}$ during the 48 hour culture. The rapid decrease of the MI resulted in the fact that it was not possible to examine enough metaphases as a result of the high cytotoxic reaction. The result of the 
other part of our study (detection of double-strand breaks by the phosphorylated $\gamma \mathrm{H} 2 \mathrm{AX}$ histone) was negative. In this part of the experiment we focused on testing the ability of the highest concentration of thiacloprid $\left(480 \mu \mathrm{g} \cdot \mathrm{ml}^{-1}\right)$ to induce $\gamma \mathrm{H} 2 \mathrm{AX}$ foci after the 4-hour exposure of human lymphocytes. The phosphorylated $\gamma \mathrm{H} 2 \mathrm{AX}$ histone is nowadays considered to be a sensitive and quantitative marker of the double-strand breaks. After the automatic evaluation by the Metafer software, we concluded that human lymphocytes did not contain a statistically significant occurrence of $\mathrm{yH} 2 \mathrm{AX}$ foci which would refer to double-strand breaks caused by thiacloprid. The results of the detection are depicted in Figures 1 and 2.

Table 1. Results of chromosome aberrations after the exposure to human lymphocytes in peripheral blood during 24 hours

\begin{tabular}{|c|c|c|c|c|c|c|c|c|}
\hline Donor & $\begin{array}{l}\text { Metaphase } \\
\text { number }\end{array}$ & G & CB & eso & CE & IE & $\%$ Breaks \pm SD & $\% \mathrm{MI}$ \\
\hline Control & 100 & 1 & 1 & - & - & - & $1.0 \pm 0.01$ & 2.6 \\
\hline \multicolumn{9}{|l|}{$\begin{array}{l}\text { Thiacloprid } \\
{\left[\mu \mathrm{g} \cdot \mathrm{ml}^{-1}\right]}\end{array}$} \\
\hline 30 & 100 & 5 & 2 & - & - & - & $2.0 \pm 0.14$ & 2.0 \\
\hline 60 & 100 & 6 & 3 & - & - & - & $3.0 \pm 0.17$ & 1.7 \\
\hline 120 & 100 & 8 & 3 & 1 & - & - & $4.0 \pm 0.20$ & $1.3^{*}$ \\
\hline 240 & 100 & 8 & 5 & 2 & - & - & $7.0 \pm 0.26^{*}$ & $1.0^{* *}$ \\
\hline 480 & 100 & 12 & 7 & 1 & - & - & $8.0 \pm 0.27^{*}$ & $1.0^{* *}$ \\
\hline $\begin{array}{c}\text { EMS } \\
250 \mu \mathrm{g} \cdot \mathrm{ml}^{-1}\end{array}$ & 100 & 10 & 10 & 2 & 1 & - & $16 \pm 0.35^{* * *}$ & $0.9 * * *$ \\
\hline
\end{tabular}

Statistical significance: ${ }^{*}-\mathrm{P}<0.05 ;{ }^{* *}-\mathrm{P}<0.01$; ${ }^{* *}-\mathrm{P}<0.001$; Control—positive control; $\mathrm{EMS}=$ ethylmethylsulfonate $\left[250 \mu \mathrm{g} \cdot \mathrm{ml}^{-1}\right]$ - positive control; G-gap; CB-chromatid break; IB —isochromatid (chromosomal) break; CE—chromatid exchange; IE-isochromatid (chromosome) exchange

Table 2. Results of chromosome aberrations after the exposure to human lymphocytes in peripheral blood during 48 hours

\begin{tabular}{|c|c|c|c|c|c|c|c|c|}
\hline \multirow{2}{*}{ Donor } & \multirow{2}{*}{$\begin{array}{l}\text { Metaphase } \\
\text { number }\end{array}$} & \multicolumn{5}{|c|}{ Types of CA } & \multirow{2}{*}{$\%$ Breaks \pm SD } & \multirow{2}{*}{$\% \mathrm{MI}$} \\
\hline & & G & CB & IB & CE & IE & & \\
\hline Control & 100 & 3 & 2 & - & - & - & $2 \pm 0.141$ & 2.4 \\
\hline \multicolumn{9}{|l|}{$\begin{array}{c}\text { Thiacloprid } \\
{\left[\mu \mathrm{g} \cdot \mathrm{ml}^{-1}\right]}\end{array}$} \\
\hline 30 & 100 & 6 & 3 & - & - & - & $3 \pm 0.17$ & 2.0 \\
\hline 60 & 100 & 8 & 6 & 1 & - & - & $7 \pm 0.26$ & 1.7 \\
\hline 120 & 100 & 12 & 7 & 1 & - & - & $8 \pm 0.27$ & 1.5 \\
\hline 240 & 100 & 13 & 8 & 3 & - & - & $11 \pm 0.31^{*}$ & $1.1^{*}$ \\
\hline 480 & ND & - & - & - & - & - & - & $0.42^{* * *}$ \\
\hline $\begin{array}{c}\text { MMC } \\
0.4 \mu \mathrm{g} \cdot \mathrm{ml}^{-1}\end{array}$ & 100 & 12 & 10 & - & 2 & - & $14 \pm 0.35^{* *}$ & $0.9 * *$ \\
\hline
\end{tabular}

Statistical significance: ${ }^{*}-\mathrm{P}<0.05 ;{ }^{* *}-\mathrm{P}<0.01$; ${ }^{* *}-\mathrm{P}<0.001$; MMC - mitomycin; $\mathrm{C}$ - positive control; $\mathrm{G}$-gap; $\mathrm{CB}$-chromatid break IB-isochromatid (chromosomal) break; CE— chromatid exchange; IE-isochromatid (chromosome) exchange; ND—none detected 


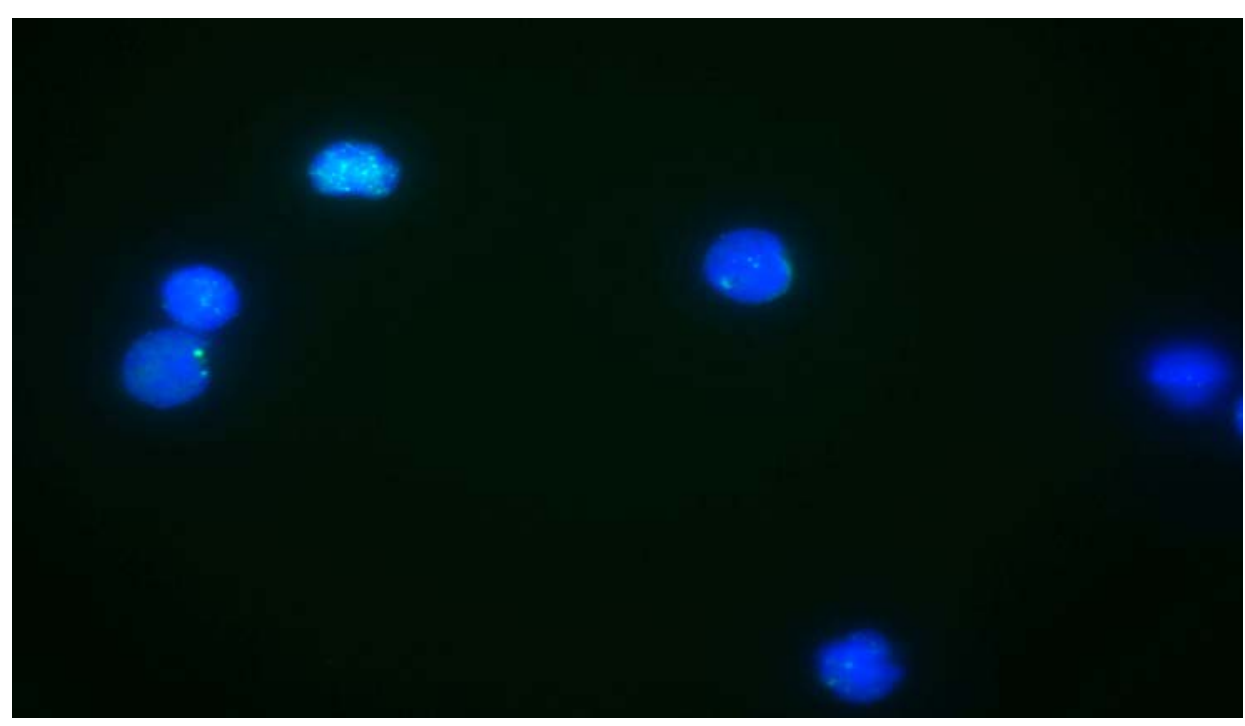

Fig. 1. Representative picture of a positive control depicting green foci stained by Alexa Fluor 488

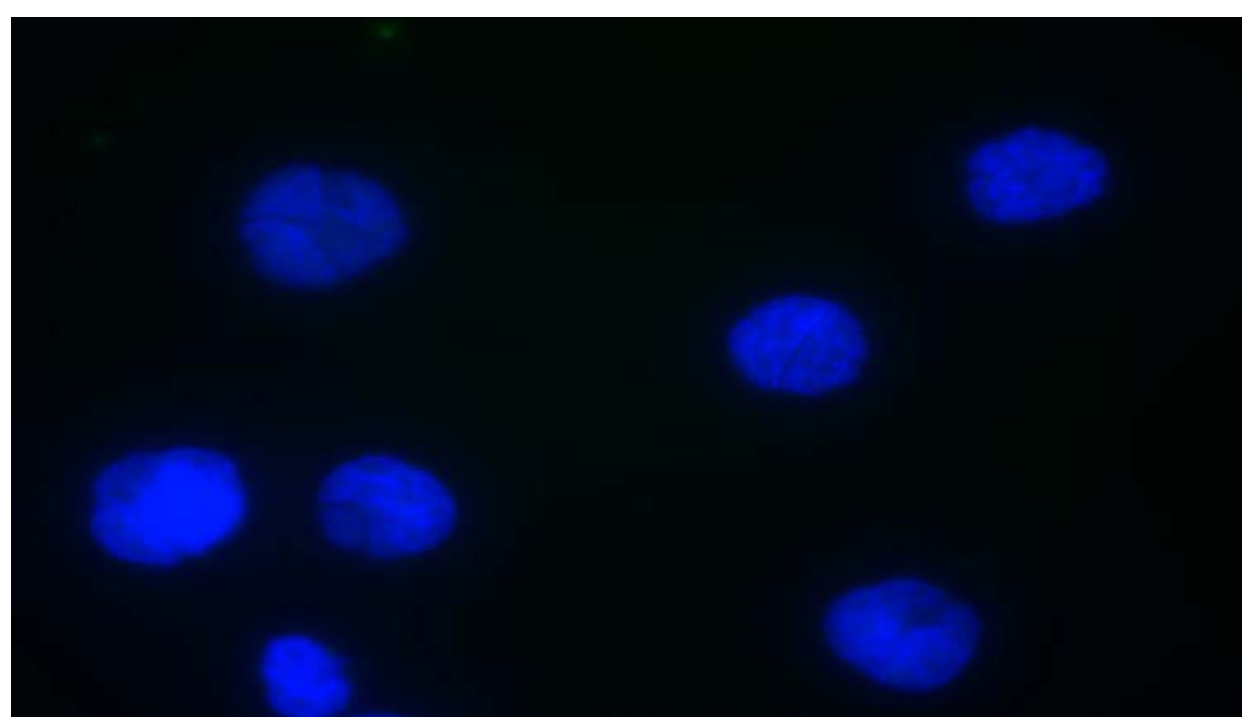

Fig. 2. Representative picture of a lymphocyte exposed to thiacloprid-no foci

\section{DISCUSSION}

Structural chromosome aberrations represent irreversible changes in the chromosome structure, which could have serious genetic consequences for a cell or an organism. In our study we focused on the detection of chromosomal breaks induced by thiacloprid in human lymphocytes. The results of our study did not confirm the genotoxic effect of thiacloprid, however, the highest tested concentration ( $480 \mu \mathrm{g} \cdot \mathrm{ml}^{-1}$ ) exerted a cytotoxic effect after the extended time of exposure.

The cytotoxicity of thiacloprid was confirmed in the in vitro experiment in cells of the Chinese hamster V79 at the concentration up to $750 \mu \mathrm{g} \cdot \mathrm{ml}^{-1}$. No other statistically significant growth of cells with chromosome abberations were observed at other concentrations [7]. On the contrary, the study of K o c a m a n et al. [6] confirmed the genotoxic effect of thiacloprid on human lymphocytes at the concentrations of 75,150 and $300 \mu \mathrm{g} \cdot \mathrm{ml}^{-1}$. The other study of Calderon-S e gura et al. [1] focused on human lymphocytes, confirmed the results of the previous experiment. In the study the authors compared the genotoxic effects of commercial preparations, such as Calypso (thiacloprid), Poncho (clothianidin), Gaucho (imidacloprid) and Jade (imidacloprid) and they detected that Jade exerted the strongest genotoxic effect. 
The other aim of our study was to detect the induction of the phosphorylated $\gamma \mathrm{H} 2 \mathrm{AX}$. Nowadays, the phosphorylated $\gamma \mathrm{H} 2 \mathrm{AX}$ histone is considered to be a sensitive and quantitative marker of the double-strand breaks.

The results of our experiment corresponded with the study of Galdík ová et al. [4], which was focused on the detection of the $\gamma \mathrm{H} 2 \mathrm{AX}$ induction after the exposure of the human cell line HT 29 to thiacloprid by the immunofluorescence method. The insecticide was used at the concentrations of $60,120,240$ and $480 \mu \mathrm{g} \cdot \mathrm{ml}^{-1}$. The results did not demonstrate the increased frequency of the DSB by using the immunocytochemical method with a microscopic visualization. C a va s et al. [2] examined the genotoxic effect of another representative of neonicotinoids-acetamiprid-on the human intestinal cells CaCo-2. However, acetamiprid did not induce the formation of the $\gamma \mathrm{H} 2 \mathrm{AX}$ foci at the same rate as the $\mathrm{H}_{2} \mathrm{O}_{2}$ positive control.

\section{CONCLUSIONS}

The results of this study showed that thiacloprid exerted cytotoxic activity at the concentration of $480 \mu \mathrm{g} \cdot \mathrm{ml}^{-1}$ at the 48-hour duration of incubation. The genotoxic or clastogenic effect on the human lymphocytes was not confirmed. By the automatic statistical evaluation using Metafer we made a conclusion that the chosen neonicotinoid (thiacloprid) did not induce statistically significant frequencies of the $\gamma \mathrm{H} 2 \mathrm{AX}$ foci.

\section{ACKNOWLEDGEMENT}

The Ministry for Education and Science of the Slovak Republic supported this study under the contracts No. IGA 09/2017 and VEGA 1/0242/19.

\section{REFERENCES}

1. Calderón-Segura, M. E., Gómez-Arroyo, S., VillalobosPietrini, R., Martínez-Valenzuela, C., Carbajal-López, Y., Calderón-Ezquerro, M. D. C., et al., 2012: Evaluation of genotoxic and cytotoxic effects in human peripheral blood lymphocytes exposed in vitro to neonicotinoid insecticides news. J. Toxicol., Epub., 2012: 612-647. DOI: 10.1155/2012/ 612647.

2. Çavaş, T., Çinkılıç, N., Vatan, Ö., Yılmaz, D., Coşkun, M., 2012: In vitro genotoxicity evaluation of acetamiprid in $\mathrm{CaCo}$ 2 cells using the micronucleus, comet and $\gamma \mathrm{H} 2 \mathrm{AX}$ foci assays. Pestic. Biochem. Physiol., 104, 3, 212-217. DOI: 10.1016/j. pestbp.2012.08.004

3. Crossthwaite, A. J., Bigot, A., Camblin, P., Goodchild, J., Lind, R. J., Slater, R., Maienfisch, P., 2017: The invertebrate pharmacology of insecticides acting at nicotinic acetylcholine receptors. J. Pestic. Sci., 42, 3, 67-83. DOI: 10.1584/jpestics. D17-019.

4. Galdíková, M., Holečková, B., Šiviková, K., Koleničová, S., Dianovský, J., 2018: Analysis of yH2AX foci after exposure of human cell line HT 29 to insecticide (In Slovak). Collective volume from the 38th International Scientific Symposium "Industrial Toxicology", Svit, 30-32.

5. Kagabu, S., 2010: Discovery of imidacloprid and further developments from strategic molecular designs. J. Agric. Food Chem., 59, 7, 2887-2896. DOI: 10.1021/jf101824y.

6. Kocaman, A. Y., Rencüzoğulları, E., Topaktaş, M., 2014: In vitro investigation of the genotoxic and cytotoxic effects of thiacloprid in cultured human peripheral blood lymphocytes. Environ. Toxicol., 29, 6, 631-641. DOI: 10.1002/tox.21790.

7. Pesticide residues in food 2006-FAO: Part II. In Proceedings from Joint FAO/WHO Meeting on Pesticide Residues Evaluations, Rome, Italy, 3-12 October 2006, 400 pp.

8. Schroeder, M. E., Flattum, R. F., 1984: The mode of action and neurotoxic properties of the nitromethylene heterocycle insecticides. Pestic. Biochem. Physiol., 22, 2, 148-160.

9. Tomizawa, M., Casida, J. E., 2005: Neonicotinoid insecticide toxicology: mechanisms of selective action. Annu. Rev. Pharmacol. Toxicol., 45, 247-268. DOI: 10.1146/annurev.pharmtox.45.120403.095930.

10. Ware, G. W., Whitacre, D. M., 2004: The Pesticide Book. 6th edn., Meister Media Worldwide, Willoughby, Ohio, 496 pp.

Received June 19, 2019

Accepted September 23, 2019 